\title{
Recent trends in the size and the distribution of inherited wealth in the UK
}

\section{Eleni Karagiannaki}

\section{Contents}

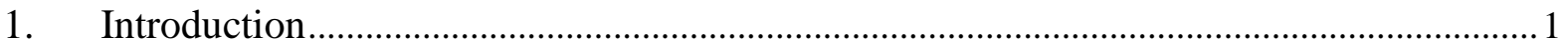

2. Brief literature review on the size of inheritance and its impact on wealth inequality..... 2

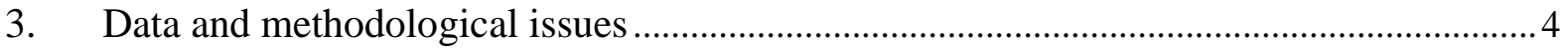

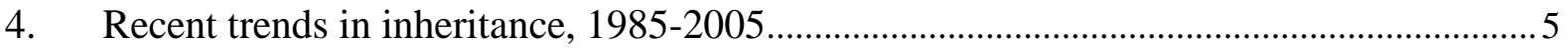

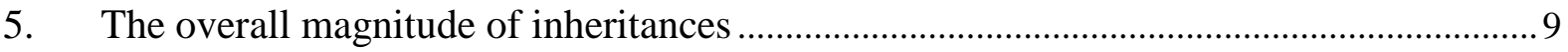

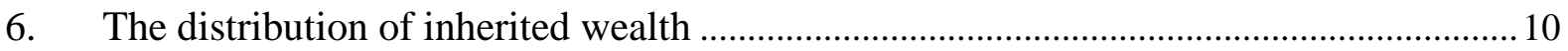

7. The correlation between inheritance and various socio-economic indicators .................. 12

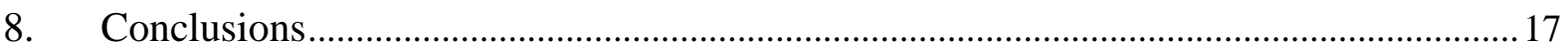

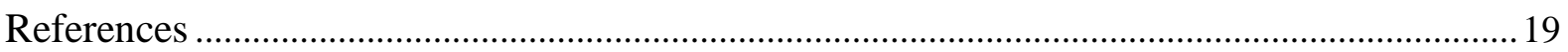

CASE/146

June 2011
Centre for Analysis of Social Exclusion

London School of Economics

Houghton Street

London WC2A $2 \mathrm{AE}$

CASE enquiries - tel: 02079556679 


\section{Centre for Analysis of Social Exclusion}

The Centre for the Analysis of Social Exclusion (CASE) is a multi-disciplinary research centre based at the London School of Economics and Political Science (LSE), within the Suntory and Toyota International Centres for Economics and Related Disciplines (STICERD). Our focus is on exploration of different dimensions of social disadvantage, particularly from longitudinal and neighbourhood perspectives, and examination of the impact of public policy.

In addition to our discussion paper series (CASEpapers), we produce occasional summaries of our research in CASEbriefs, and reports from various conferences and activities in CASEreports. All these publications are available to download free from our website. Limited printed copies are available on request.

For further information on the work of the Centre, please contact the Centre Manager, Jane Dickson, on:

Telephone: $\quad$ UK+20 79556679

Fax: $\quad$ UK+207955 6951

Email: $\quad$ j.dickson@1se.ac.uk

Web site: http://sticerd.lse.ac.uk/case

(c) Eleni Karagiannaki

All rights reserved. Short sections of text, not to exceed two paragraphs, may be quoted without explicit permission provided that full credit, including (C) notice, is given to the source. 


\title{
Editorial Note and Acknowledgements
}

Eleni Karagiannaki is a Research Officer at the Centre for Analysis of Social Exclusion, London School of Economics (email e.karagiannaki@1se.ac.uk). Data for the BHPS, AIS and GHS were made available by the UK Data Archive. Financial support from the Nuffield Foundation is gratefully acknowledged. The author is also grateful to Tom Sefton for the calculation of housing wealth data in the British Household Panel Survey as well as Jon Aldous from HMRC for providing estates statistics. Also the author would like to thank Tania Burchardt, Francesca Bastagli John Hills, Frank Cowell, Howard Glennerster, Abigail McKnight, Tom Sefton as well as members of Nuffield Advisory Committee (including Athena Bakalexi, James Banks, Chris Curry, Joanna Littlechild, Karen Rowlingson, Holly Sutherland, Steve Wilcox) for useful comments and suggestions. All errors and ambiguities are the author's responsibility.

\begin{abstract}
Abstract: In this paper we document the evolution of the annual flow of inheritances in the UK during the period 1984-2005 and provide estimates for the overall magnitude and the distribution of inherited wealth. Our results indicate that the period under examination the annual flow of inheritance increased markedly, from $£ 22$ billion in 1984 to $£ 56$ billion in 2005 . The main drivers behind this increase were the rise in house prices and to a lesser extent the increase in the proportion of inheritances which included housing assets. Our results, based on analysis of survey data, show that the distribution of inheritances is characterized by a very high degree of inequality (comparable by and large to that observed in personal wealth) and that this has increased over time. However, the inequality increasing effect from the greater inequality in the distribution of inheritance was counterbalanced by the increase in the percentage of the population who received an inheritance. Our results also show that inheritance is positively associated with socio-economic status and that the disparities between groups became slightly more pronounced over time (mainly across educational groups). However, our evidence also shows that inheritance for the majority of recipients is fairly small and that large inheritances are limited to a very small minority of the population.
\end{abstract}

Keywords: Inheritance, wealth, intergenerational transfers, inequality JEL numbers: D10, D31 


\section{Introduction}

Over the last years there have been widespread debates on the extent to which inheritance as a source of wealth accumulation is growing in importance. In a recent paper Piketty (2011) showed that this was indeed the case in France (where that the annual flow of inheritance in France rose from less than 5 per cent of national income in 1950 to 15 per cent of the national income in 2010 (with an acceleration of trend after the 2000s) and that the main factor accounting for this trend was that the growth rate of the economy was lower than the rate of return of private wealth.

In the UK interest in inheritance increased over the last twenty years (or so) in connection with the rise in housing wealth. Many scholars have conjectured that the rise in the accumulated housing wealth (which resulted from the growth in owner occupation since the post war and the house price inflation of late 1980s and 2000s) combined with the slow rate of wealth decumulation (even at very old ages) will gradually lead to an increase in the size of inheritance as younger generations of older people die and bequeath their wealth. Although previous analyses have shown that until the late 1980s there has been no particular increase in the number of inheritances which include housing assets (Hamnett, 1992) projections undertaken during the early 1990s suggested that the numbers of inheritance will double by 2025 as the post war generation of mass home owners gradually die and bequeath their property (Hamnett, Harmer and Williams, 1991). However, more recent studies revising mortality assumptions downwards showed that the increase in housing inheritance will be much more moderate than initially anticipated (Holmans, 2008). In contrast to the trends concerning the number of housing inheritance studies analysing the trends in the value of housing inheritance showed that during the period 1969-1988 the value of inheritance which included housing assets has grown substantially (Hamnett,1992). This increase was entirely the result of the house price inflation over the period (Hamnett, 1992). Holmans (2008) projected further increases in the value of housing inheritance by 2025 but stressed again the process will be slower than it has been initially anticipated. Given these prospects an issue which has been debated at length in the UK was the effect of housing inheritance on wealth inequality. Some researchers have argued that housing inheritance will have equalizing effects on the distribution of wealth stressing the fact that housing wealth is more widespread than other forms of wealth while others argued that housing inheritance will contribute to greater wealth inequality, pointing to the concentration of wealth in the housing market (Hamnett, 1991). Holmans and Frosztega (1994) analyzing a specially commissioned UK survey show that 80 per cent of inheritors to be above age 30 but argue that, although the main beneficiaries of past house price inflation are people who are already home owners and thus have substantial assets of their own, the overall impact of these patterns on the overall distribution of wealth will be relatively modest.

This paper uses more recent data than prior analyses to determine the extent to which the number and the value of inheritances grew in the UK over the period 1985-2005 
and to assess the impact of housing inheritance within the observed trend. In addition, combining inheritance data from three different micro surveys it provides a detailed analysis of the distribution of inheritance and its changes over time. For our analysis we rely on the HMRC published statistics on estates passing on death covering the period 1984-2005, the 2004 Attitudes to Inheritance Survey (AIS) which provides information on lifetime transfers, as well as the 1995/96 General Household Survey (GHS) and the British Household Panel Survey (BHPS) which provide respectively information on inheritance received during the period 1986-1995 and 1996-2005. Throughout the paper our focus will be on intergenerational inheritance since these are more directly relevant on debates about the intergenerational transmission of wealth inequality.

The remainder of the paper is structured as follows. Section 2 begins by providing a brief review of the literature on the quantitative importance and the distributional impact of inheritance. Section 3 describes the data while sections 4-7 describe the results of our analysis. Section 4 describes the results concerning the trends in the rate and value of inheritances while Section 5 provides estimates on the overall size of inheritances. Then Section 6 provides estimates of the degree of inequality of inheritances and the extent to which inequality of inheritance have changed over time. Section 7, then moves to explore the correlation of inheritance with various measures of socio-economic status and to determine how this has changed over time. The final section concludes with a brief discussion of the main findings of the paper.

\section{Brief literature review on the size of inheritance and its impact on wealth inequality}

Historically inheritance was a key part of the perpetuation of wealth inequality and the preservation of largest fortunes from generation to generation. However as the importance of old money declined after both World Wars and as middle class wealth spread, particularly through home ownership the role of inheritances has become more ambiguous. Empirical studies differ substantially both in the relative importance they assign to inheritance as a source of wealth and in whether it has equalising or disequalising effect on the distribution of wealth. Based on survey data some US studies suggest that inherited wealth accounts for as little as 13 per cent of total net worth (Smith, 1999) while others put the respective estimates at much higher values. For example, Wolff (2002) provides estimates of the magnitude of 19-35 per cent (depending on the degree of capitalization of inherited wealth) while Gale and Scholtz, (1994) suggest that parental inter vivos transfers account for at least of 20 per cent of aggregate net worth, and accumulated bequests - monetary transfers received after the death of parents - amount to 30 per cent of aggregate net worth in the US economy. Estimates for Sweden (Klevmarken, 2004) put the size of transfer wealth (inheritance and gifts) somewhere in the range of 10-19.5 per cent (depending on capitalization assumptions) while for the UK the Royal Commission on the Distribution of Income and Wealth estimated that in the UK inherited wealth accounted for about 20 per cent of total wealth in 1973 (as estimated by the estate duty 
method) with the estimate rising to 25 per cent by including gifts made more than 7 years before death and exempt property (Royal Commission on the Distribution of Income and Wealth, 1977). Kotlikoff and Summers (1981, 1988), estimating transfer wealth by subtracting lifecycle wealth (defined as the accumulated net surplus of earnings over consumption) from net worth, estimate that transfer wealth accounts for at least 80 per cent of total US net worth. Modigliani (1988a, 1988b) adjusting Kotlikoff and Summers' calculation for a number of factors estimates, by contrast, that transfer wealth accounts for 20 per cent or less of total net worth. The large discrepancy in the two estimates arises from a difference in the definition of transfers used by the authors as well as from the treatment of income from inheritance to wealth accumulation. In a thorough review of the literature Davies and Shorrocks (2000) conclude that a reasonable rough estimate is that inheritance contributes some 35-45 per cent to aggregate wealth.

In addition to the controversy over the size of inherited wealth, theoretical studies vary with respect to their conclusions on whether inheritance makes the distribution of wealth more or less equal. As stressed by Gokhale et al. (2001) the reason for the controversy over the impact of inheritance on wealth inequality is the complexity of inheritance-bequest process and the fact that a number of factors may intervene into this process (including earnings inequality, the intergenerational transmission of earnings inequality, the number and spacing of children, assortative mating etc) ${ }^{1}$. Depending on the assumptions used different studies reach to different conclusions. Some suggest that inheritance can be equalising reflecting the role of imperfect correlation of spousal backgrounds (Laitner, 1979a and b), the tendency of parents to either distribute their estates equally among children (Stiglitz, 1969) or to leave more to less well off children (Becker and Tomes, 1979; Tomes 1981). Others with equally convincing arguments point to ways by which inheritances can have disequalising effect with respect to the distribution of wealth (Davies, 1982; Gokhale, 2001; De Nardi, 2004).

In contrast to the controversy regarding the impact of inheritance on the distribution of wealth, studies that examine intergenerational wealth mobility consistently find that the degree of intergenerational wealth correlation is very high and that inheritance plays a very substantial role in shaping the top end of the wealth distribution (Wedgwood 1928, 1929; Harbury, 1962; Harbury and McMahon, 1973; and Harbury and Hitchens 1976, 1979). ${ }^{2}$ While this work is very interesting, there are two reasons why it may fall short in establishing the direct link between inheritance and wealth inequality. First, the data used by these studies relate to estates left by the fathers and not to inheritance received by the sons. Secondly these studies fail to establish that the relationship between inheritance and intergenerational wealth correlation is causal (note that there may be many reasons why parents' and sons' wealth may be correlated other than inheritance).

$1 \quad$ For a fuller discussion see Gokhale et al. (2001).

2 Note however that Harbury and Hitchens (1979) found some evidence of a decline in the relative importance of inherited wealth among top wealth holders over time 


\section{Data and methodological issues}

The data for this paper are drawn from four sources. The most baseline data comes from the HMRC (formerly Inland Revenue) published statistics on estates passing on death. These statistics are based on Inheritance Tax records which are gathered by HMRC in the course of administering Inheritance Tax (introduced in 1986) and its predecessor Capital Transfer Tax. The principal source of these data is applications for grant representations which gives the deceased's personal representatives legal authority to deal with the estate. Probate is required for most estates including those passing to surviving spouses although these are exempt from Inheritance Tax. The only estates that are excluded from this requirement are low value estates - generally worth less than $£ 5,000$ - or estates which are held in joint names and which pass to surviving spouse/civil partner (HMRC, 2011a). In 2006, the estates notified for probate represented about 50 per cent of all estates. ${ }^{3}$

In addition to HMRC's published statistics on estates passing on death, we also draw evidence from the three major UK micro surveys. The first is the British Household Panel Survey, a nationally representative panel survey of about 5,500 private households (containing more than 10,000 individuals) which has been conducted annually from $1991{ }^{4}$ The survey aims to interview all adults (over 16 years old) from the original sample in successive waves and, if they split-off from original households to form new ones, all adult members of their new households are also interviewed. Children in sample households become full sample members when they reach age 16 (there is however a special survey of 11-15 year old household members from wave four onwards). BHPS contains rich information on a range of issues. Information on inheritance receipt in BHPS was collected continuously from wave 7 onwards as part of more general questions of windfall payments received by the respondent in last 12 months prior to the survey. In this paper we use data for inheritances recorded in all waves from wave 7 to wave 16 - which broadly cover inheritances received during the period 1996-2005. ${ }^{5}$

The second survey that we use is the AIS, a specialised nationally representative survey of more than 2,000 individuals which was conducted in 2004 by researchers

Own calculations based on statistics on the total number of UK deaths and estates notified for probate (2002-3 to 2006-7) Table 12.3, available from the HMRC website at http://www.hmrc.gov.uk/stats/inheritance_tax/table12-3-iht-sept09.pdf.

Originally, a stratified random sample of households was drawn at the start of the survey, then all residents of those households were traced and re-interviewed each year, to generate annual panel records which have been collected ever since.

The BHPS interviews take place in the Autumn of each year, mainly in September and October, so strictly speaking inheritances reported in 1997, for instance, relate to a period generally including the last quarter of 1996 and the first three quarters of 1997. For simplicity, we refer here to them as being within the year when the reporting period started. Also note that in wave 5 BHPS recorded whether respondents have received an inheritance but not the value of their inheritance (and for this reason we exclude wave 5 inheritance data from our analysis). 
from Bristol and Bath universities in order to study the importance of inheritances and inheritance intentions. ${ }^{6}$ The data collection method for inheritances in AIS was based on recall. Respondents were asked to indicate whether they had received any inheritances, gifts or other types of wealth transfers in the past and to specify the particular type, value and the date at which each of the three more recent transfers was received. Since the value of inheritance in AIS is recorded in bands to obtain a continuous value for each inheritance, each individual is assigned the mid-point of their reported band. ${ }^{7}$ Given that the bands in AIS are relatively wide they cannot provide a precise estimate of the value of inheritance. They can however provide an indication of the direction of any observed changes.

The third dataset that we use is the 1995/96 General Household Survey (GHS). This specific cross-section of the GHS contained a special supplementary module which asked respondents to indicate whether they had received any inheritance of more than $£ 1,000$ (in cash terms) in the 10 years prior to the survey (but excluding any interspousal inheritance) as well as the value, the type and the year of receipt of each reported inheritance. The problem with the $£ 1,000$ cash cut-off in GHS is that it excludes an increasingly larger proportion of smaller inheritance in earlier years. In order to account for this bias and to ensure that we exclude inheritance of similar real value in each year we exclude inheritances below $£ 2,000$ at 2005 prices (which is the real value equivalent of $£ 1,000$ in 1985 at 2005 prices). Note that in all surveys we express inheritances in constant 2005 prices using the retail price index (on the basis of the value and the date of receipt of each inheritance) and we exclude inter-spousal inheritance (given the focus of the paper and the constraints of the GHS data). ${ }^{8}$ Since in our across time comparisons we consider differences between GHS and BHPS data we apply this real price threshold in both surveys (given that the value of inheritance in AIS is recorded in bands and so we cannot apply this threshold to AIS).

\section{Recent trends in inheritance, $\mathbf{1 9 8 5 - 2 0 0 5}$}

In this section we examine trends in the flow of inheritances in each year during the period 1985-2005 and we assess the role of housing inheritance within any observed trend. We start our analysis with Table 1 and Figure 1 where present HMRC's statistics on the number and the total value of estates passed on death for the period 1985-2005. Statistics are presented for all estates as well as by whether the estate

6

Although the original sample design in AIS was designed as a regionally stratified clustered sample due to difficulties the sampling strategy was switched to a quota design. Overall, about 50 percent of the cases were based on random sampling and 50 percent on quota sampling.

7 We set the value of the open ended top category at $£ 300,000$ which was the mean value of inherited wealth above the value of 200,000 in BHPS.

Inter-spousal inheritances are explicitly excluded in GHS. In AIS we exclude inter-spousal inheritance by exploiting survey information about the donor of inheritance while in BHPS by excluding inheritance received by persons who became widows/ers between waves. 
includes housing assets or financial assets. One thing to note from this table is that although the number of estates remained fairly stable throughout the period 19842005 , from the early 2000s onwards there has been an significant increase in the proportion of estates which included housing assets (from 58 per cent in 1984/85 to 65 per cent in 2005/06). This increase which is likely to reflect the fact that the first generation of mass home-ownership are gradually reaching the end of their lifetime contrasts to the earlier trend documented by Hamnett (1992) who found that the number of housing estates had not changed significantly during the period 1968/69$1987 / 88$. Another thing to note from Table 1 is that the value of estates during the period under examination rose in real terms from $£ 22.2$ billion in $1984 / 85$ to $£ 55.7$ billion in 2005/06 (a £33.5 billion increase). This took the flow of inheritance from being the equivalent of 3.1 per cent of GDP in 1984/85 to around 4.4 per cent in 2005/06. ${ }^{9}$ Examination of the trends by whether the estates include financial and/or housing assets reveals a substantial increase in the value of estates which included financial assets (from around $£ 12.3$ billion in 1984/85 to $£ 25.6$ billion in 2005/06) and an even sharper increase in value of estates which included housing assets (reaching to $£ 30.1$ billion in 2005/06 from $£ 9.8$ billion in 1984/85). Given that the overall number of estates remained fairly stable the average value of estate increased from $£ 81,000$ in $1984 / 85$ to $£ 204,000$ in 2005/06 (Figure 1c). The secular changes in the mean value of estates tracked closely the growth in the mean value of housing assets closely (which increased from $£ 63,500$ in $1984 / 85$ to $£ 169,700$ in $2005 / 06$ ): it decreased during the housing market downturn of the early 1990s and increased steadily after the recovery of the late 1990s with a much sharper growth during the house price boom period of the early 2000s (as can be seen from Figure 1d during the period 1986-2005 average house price). Since almost all estates contain financial assets (with or without housing) the average value of these rose in line with their total value, from $£ 45,300$ in $1984 / 85$ to $£ 94,300$ in $2005 / 06$. This increase was much smaller and steadier than that restricted to estates containing housing assets.

The HMRC statistics reported above refer to all estates including many where all or part passes to surviving spouses. Since our main interest in this paper is on intergenerational inheritance it would be useful to examine the evolution of estates which exclude inter-spousal estates. Although HMRC does not produce statistics on non-spousal estates we can generate a crude estimate for these based on the value of estates of not married people (widowed, singles or divorced) plus a fraction of the value of estates of married people. ${ }^{10}$ Table 2 report these estimates. As with all estates the statistics suggest that the value of non-spousal estates increased substantially during the period under examination, reaching to $£ 39.3$ billion in 2005/06 from around $£ 18$ billion in 1986/87.

9 Note that this remains much lower, however, than the recent estimates of Piketty (2011) for France.

In our calculation we assume that about 17 per cent of estates of married people went to persons other than spouses (based on HMRC estimate on the distribution of the value of bequests by relationship to the beneficiary as reported in Table 12.9 in HMRC website). 
Given the above described trends we now turn to examine the extent to which the increase in the value of estates was translated in an equivalent increase in the value of inheritance and to explore whether there has been any change in the percentage of inheritors over time. To explore patterns of inheritance we rely on the three survey sources described in the data section: AIS, GHS and BHPS. Based on BHPS we can directly derive estimates on the rate and the value of inheritance that were received annually from 1996 to 2005 while based on GHS and AIS we can infer the rate and the value of inheritances received in earlier years by exploiting information of the year of receipt of each reported inheritance. Because the data collection method in AIS and GHS is based on recall, data on inheritance in both surveys may be hampered by recall error and under-reporting bias. Also given the retrospective nature of inheritance data in these two surveys a number of inheritors in earlier years may have died by the time of the survey. The estimated number of inheritance will therefore be an underestimate of the true number of inheritances received in earlier years. To account for the latter source of bias we weight past inheritances by an appropriate age-sex specific mortality factor to account for the fact that a number of inheritors in earlier years may have died by the time of the survey. In order to minimise measurement error due to the relatively small sample size of inheritors in each particular year we aggregated inheritances into four periods: (i) 1986-1990; (ii) 1991-1995; (iii) 1996-2000 and (iv) 2001-2005. ${ }^{11}$ For each of these periods we provide statistics for the average annual rate of inheritance calculated by dividing the percentage of inheritors in each time period by the number of years which span each period - and the average size of inheritance. Two set of results are reported for each. The first (presented in the right panel of Table 3) refers to all inheritances irrespective of their value (but with some financial value) and is based on AIS and BHPS while the second (presented in the left panel of Table 3) refer to larger inheritance - i.e. those valued more than $£ 2,000$ in 2005 prices and is based on GHS and BHPS.

Consistently with the estates statistics, the results in Table 3 suggest that the percentage of people who received inheritance in each year during the period 19952005 remained fairly stable (ranging between 2.2 per cent in AIS and 2.4-2.5 per cent in BHPS). The small increase detected in AIS between 1991-1995 and 1995-2004 (from 1.9 to 2.2 per cent) is rather small especially considering the possibility that recall error bias for earlier period would be larger. Contrasting to that, the GHS statistics imply an increase in the percentage of people who received an inheritance above the $£ 2,000$ threshold from an average of 0.8 in the period 1986-1990 to 1.2 per cent in the period 1991-1995 while throughout the following period (1996-2005) BHPS shows that 1.4 per cent of people received inheritance above the $£ 2,000$ threshold suggesting a further increase. Given that the number of estates and the percentage of all inheritances remained fairly stable during this period, this increase suggests a rise in the number of inheritances above the $£ 2,000$ real threshold. An important consideration for this trend however is whether (or to what extent) the implied increase is contaminated by recall error bias intrinsic to the retrospective of 1996 and of 2001, respectively. 
nature of the inheritance data in the GHS. Although it is difficult to determine the degree of recall error bias, the fact that Holmans and Frosztega (1994) produced estimates for the number of inheritances above $£ 1,000$ (in real 1980s terms) for the period 1986-1990 which are of the same order as GHS suggests that at least to a certain extent the difference between BHPS and GHS reflect a genuine increase in the number of larger inheritances. ${ }^{12}$ A further observation that one can make based on BHPS statistics is that about 40-45 per cent of all inheritances received in any particular year are worth less than $£ 2,000$ in constant 2005 prices (excluding small inheritances in BHPS decreases the estimate of the annual rate of inheritance by about 1 percentage).

Within each survey the change in the value of inheritance match closely the patterns which emerged based on HMRC statistics: they suggest a decrease in the average real value of inheritance during the early 1990s and a growth from 1995 onwards. However, despite the fact that AIS and BHPS imply similar patterns for comparable time periods the estimates based on AIS are considerably larger than the BHPS ones. In part the difference between AIS and BHPS may reflect a recall error bias and a resulting tendency of respondents in AIS to remember larger bequests (however the difference in the inheritance rate between the two surveys is rather small to explain the difference). Aggregating the GHS and BHPS statistics at national level we find that the total value of inherited wealth increased from an average of around $£ 12$ billion per year in 1986-1990 to an average of $£ 24.8$ billion per year in 2001-2005. This represents a 107 per cent increase. By comparison our estimates of non-spousal estates based on HMRC statistics suggest that non-spousal estates increased from an annual average of around $£ 19.6$ billion in the period 1986-1990 to $£ 37.0$ billion in 2001-2005 (or by about 80 per cent). ${ }^{13}$

To complete the analysis on the trends in Table 4 we report statistics for the rate and value of inheritances, according to the type of asset that they correspond based on GHS and AIS (BHPS does not contain data on type of inheritance). Given the available data we consider three types of assets: 'house property', 'other assets' and 'both house property and other assets'. ${ }^{14}$ Before discussing the results of this table we

Although Holmans and Frosztega (1994) analysis is also based on retrospective data - of inheritance over $£ 1,000$ received in ten year period 1980-1990 as reported by respondents in 1990 - the period 1985-1990 is closer to the date of their data collection and therefore less susceptible to recall error bias. According to Holmans and Frostzega the period 1986-1990 the number of inheritance of more $£ 1,000$ (in 1980s prices) ranged between 257,000 and 409,000 which corresponds to an annual inheritance rate of 0.6 and 0.9 per cent respectively.

From these statistics we can also see that GHS and BHPS capture 61 and 67 per cent respectively of non-spousal estates. Given that these estimates are pretty close we can argue that recall error bias in GHS seems to be relatively small.

The 'house property' category includes inheritances which contain house property and share in house property; the 'other assets' category contain money, savings, stocks, shares, trust or other investments; while the 'both house property and other assets' include inheritance consisting of both housing and other assets (the latter included because it was not possible to disaggregate the value that corresponds to each particular type of inheritance for inheritance comprising of more than one type of asset). 
need to note that while GHS includes a separate category for money from Executors' sale of a property (which we include in the 'house property' category) in AIS we cannot distinguish between money from Executors' sale of a property from other assets (nor can we be completely sure under which category these are recorded). This methodological constraint along with the fact that GHS excludes smaller inheritances rules out any reasonable comparison between the two surveys. However, there are two interesting things to be noted from the table. First, according to the statistics of the table there is no particular trend in terms of the rate of housing inheritance in either of the surveys. Secondly, similarly to the patterns emerging from the HMRC estate statistics, the table shows a clear time trend in the value of housing inheritance. This trend is characterised by a decrease in the early 1990s and an increase from the late 1990s onwards and throughout the early 2000s. During the same period the value of inheritance which included 'only other assets' did not change in any significant way.

All in all, the evidence presented so far suggests that the period 1985-2005 there has been a marked increase in the value of inherited wealth. The main driver of this increase was the rise in the value of housing inheritances which itself was mainly driven by the increase in house prices and to a lesser extent the growth in the percentage of inheritances which include housing assets. The evidence also suggests that while the overall number of inheritances has not changed significantly during the period under examination, after the early 1990s there has been an increase in the number of larger inheritances (methodological differences preclude any safe conclusions on the extent of this change). In aggregate the BHPS figures imply an average total flow of non-spousal inheritances of about $£ 30.6$ billion for each year during the period 2001-2005. For the same period the HMRC statistics presented in Table 2 imply an average annual flow of non-spousal inheritance of about $£ 37$ billion. Excluding expenses and inheritance tax this figure would fall to about $£ 35$ billion per year for the period 2001-2005 which is only a tenth higher than the corresponding estimate based on BHPS (but note that the estate statistics exclude relatively small estates which are captured by BHPS). From the HMRC statistics we also know that these inheritances stemmed from around 200,000 non-spousal estates each year with an average size of $£ 175,000$. HMRC published statistics on the number of bequests for 2001 suggest that on average each estate in 2001 generated 4.6 inheritors with the estates of married people and non-married people generating 2.3 and 6.0 inheritors respectively. ${ }^{15}$

\section{The overall magnitude of inheritances}

In this section the aim is to provide a rough estimate of the overall size of inherited wealth in the UK in 2004 and to compare it with the estimate of the Royal Commission of Income and Wealth which dates back to the 1970s. This estimate

15

HMRC Table 12.9: Distribution of the value of bequests by sex and marital status of deceased and relationship to beneficiary, United Kingdom: deaths 2000-01.

http://www.hmrc.gov.uk/stats/inheritance tax/table12 9.pdf 
suggests that in the UK in 1973 inherited wealth was the source of about 20 percent of aggregate net worth (rising to 25 per cent by including gifts made more than 7 years before death and exempt property).

To derive our estimate we first calculate the value of all inheritances ever received by AIS respondents using two different assumptions regarding the rate of return of past inheritances: first using a zero rate of return and then setting the rate of return to 3 per cent. Under the zero rate of return assumption the average value of inheritances in AIS is estimated at about $£ 15,000$ while under the 3 per cent rate of return the estimate rises to $£ 26,600$. Aggregating these estimates to national levels put the estimate of total inherited wealth in 2004 at around $£ 705$ billion (under the zero rate of return assumption) and $£ 1,250$ billion (under the assumption of 3 per cent of rate of return). This compares to HMRC estimates for total marketable wealth of $£ 4,300$ and $£ 5,005$ billion in 2003 and 2005 respectively (both expressed in 2005 prices). Assuming that total marketable wealth in 2004 was at the mid-point of the 2003 and 2005 estimates we get an estimate of total marketable wealth for 2004 of $£ 4,600$ billion. This gives a ratio of inherited to marketable wealth of 16 per cent under the assumption of zero rate of return and 28 per cent under the assumption of three per cent rate of return. Both figures are pretty close to the estimates of the Royal Commission of Income and Wealth which suggested that the size of inherited wealth in 1973 was 20 per cent of aggregate wealth. It appears therefore that despite the increase in the value of inheritance that was documented in the period 1996-2005 the overall size of inheritance has not changed yet to any significant degree (note that the Royal Commission of Income and Wealth estimates include inter-spousal transfers). This finding supports Holmans and Frosztega's (1994) conclusions that the impact of inheritance on the distribution of wealth will occur rather slowly. It is important to stress however that our estimates were based on the rather strong assumption that all inheritances that were ever received have been saved. To the extent that there are behavioural effects to the receipt of inheritance we overestimate the true value of wealth that can be traced to bequests. On the other hand the 3 per cent rate of return we used to capitalise inheritance is probably rather low for some individuals especially those who used their inheritance to buy a house in periods of low house prices and who benefited by the house price growth in later time periods. Given the ambiguity of these assumptions the above estimates can only be perceived as providing rough estimates of the overall value of inherited wealth received by the UK population by 2004 .

\section{The distribution of inherited wealth}

The first step in understanding the impact of inheritance on wealth inequality is to examine the degree of inequality in inheritances. Likewise to understand the extent to which the impact of inheritance on wealth inequality has changed over time we need to consider how inequality in inheritance have changed over time. Table 5 presents various summary statistics characterising the distribution of inheritances based on AIS, BHPS and GHS. The first two columns of this table present statistics for the 
distribution of inheritance of any financial value based on AIS and BHPS while the last two columns present statistics for the distribution of larger inheritance based on comparable data from GHS and BHPS which cover respectively the periods 19861995 and 1996-2005. The sample we used includes respondents with non-missing inheritance data. For BHPS we select our sample among all wave 16 respondents who were observed in all ten waves prior their wave 16 interview (and therefore have complete inheritance history during the 10 years window 1996-2005). This restriction excludes all respondents younger than 25 years old in their wave 16 interview (since BHPS interviews adults when they reach the age of 16 , for individuals younger than 25 years old inheritance history would be incomplete). For comparability we applied the same age restriction to all surveys.

Overall, according to the statistics in Table 5, 43.9 per cent of AIS respondents had received an inheritance during their lifetime and up to the survey year while the mean and median value of their inheritance were about $£ 42,200$ and $£ 9,400$ respectively. By comparison the BHPS data suggest that during the ten years period 1996-2005 about 19.5 per cent of BHPS respondents had received an inheritance while the mean and median value of their inheritance were $£ 35,000$ and $£ 7,600$ respectively. Restricting the sample of inheritors to those who had received larger inheritance reduces the percentage of inheritors to about 12.5 per cent and increases the mean and the median value of their inheritance to $£ 47,800$ and $£ 16,800$ respectively. In GHS which includes comparable data on larger inheritance for the preceding ten year time period (1985$1995)$ the percentage of inheritors was about 8.4 per cent while the mean and median value of their inheritances was $£ 35,100$ and $£ 16,000$ respectively. The large difference in the mean and median value of inheritance and their differential growth over time (as shown by the BHPS and GHS comparisons) suggests a high and growing degree of inequality within the distribution of inheritance. The high degree of inequality in the distribution of inheritances is also suggested by all inequality measures. In AIS, which includes retrospective data on all inheritances, the Gini coefficient among the sample of inheritors is 0.75 while among all respondents the value of Gini increases to 0.90 . In BHPS the Gini coefficients among inheritors and among all respondents are 0.74 and 0.96 respectively. The degree of concentration as suggested by the shares of inheritance received by the top 1,5 and 10 per cent of inheritors is also very high in both surveys. According to AIS the top 1 per cent of inheritors had received about 12 per cent of the total inherited wealth so far in their lifetime while the top 5 and 10 per cent received 42 and 62 per cent of the total respectively. The degree of concentration of inheritance in BHPS is broadly similar. By comparison the Gini coefficient of personal wealth in 2005 (according to HMRC statistics on total marketable wealth Series C) was 0.66 while the share of wealth held by the top 1,5 and 10 per cent of the population were 21,40 and 54 per cent respectively. Therefore, with the exception of the degree of concentration at the top 1 per cent all other measures suggest that the inequality in inheritance is considerably higher than that of wealth. The lower degree of concentration over the very top of the distribution (top 1 per cent) reflects either the division of larger estates and/or the fact that survey data are unlikely to be accurate at the very top of the distribution. Alternatively it may signify that the relative importance of inter vivos transfers may increase with wealth due to tax considerations. 
The results in Table 5 reveal two contrasting trends concerning the patterns of the change in the distribution of inheritances over time. ${ }^{16}$ On the one hand, all measures suggest an increasing degree of inequality in the distribution of inheritance (those valued more than £2,000) among inheritors, with the Gini coefficient increasing from 0.62 in GHS to 0.66 in BHPS and the shares of inheritance received by the top 5 and 10 per cent of inheritors increasing from 29 and 44 per cent in GHS to 34 and 50 per cent in BHPS. On the other hand, all measures suggest a decreasing degree of inequality of inheritances among all respondents. This decrease was entirely the result of the increase in the share of the population who received inheritance over the period. ${ }^{17}$

Overall, the evidence presented in this section suggests that the distribution of inheritance is characterised by a high degree of inequality. The increase in the value of inheritance over the period 1986-1995 and 1996-2005 has increased the inequality in the distribution of inheritance from the already high levels. However, this increase was counterbalanced by the rise in the proportion of the population who had received inheritance. The net effect of both trends was a small degrease in the degree of inequality in the distribution of inheritance in the population as a whole.

\section{The correlation between inheritance and various socio-economic indicators}

The next step to understand the distributional impact of inheritances is to examine the association between inheritance and socio-economic status. ${ }^{18}$

Table 6 shows the percentage of individuals who had received inheritances and the mean and median value of their inheritance by age, income, financial wealth and educational level for AIS and BHPS (applying the same sample selection criteria as in the previous section). All characteristics are defined in terms of the respondents' characteristics at the time of the survey. By definition this raises some endogeneity

Given the different degree of accuracy across surveys over the very top of the distribution and in order to achieve comparability we exclude two outlier observations from GHS.

One factor that may affect the conclusions concerning the distribution of inherited wealth is that recall bias may affect smaller inheritances more seriously than larger ones.

Previous studies which look at the association between inheritance and socio-economic status include Rowlingson (2005), Holmans and Frosztega (1994), Hamnett, (1991), Hamnett et al., (1991), Lloyd (2008), and Ross et al. (2008). We extend these studies by providing a more thorough analysis of the distribution of inheritance across groups i.e. by looking both at the differences in the probability of receiving an inheritance as well as differences in the mean and median values of inheritance. Most studies to date mainly concentrate on differences in the probability of having received an inheritance (either any inheritance or an inheritance above a certain threshold). The few studies which examine differences in the value of inheritance only at differences at the mean values. Given the large skewness observed in the distribution of inheritance it is important to take a more thorough look at the patterns of inheritance. 
issues when we examine the relationship between financial wealth and inheritances (given that financial wealth level in the interview year may be the result of a previous inheritance).

As expected, both surveys suggest that the probability of inheriting rises with age. In AIS where the data cover lifetime receipts the percentage of inheritors rises from about 36 per cent for individuals under the age of 35 , to about 49 per cent for those between 55 and 74 years old and then decreases for the oldest age group (to 37 per cent). The mean and the median value of inheritances follow a similar age pattern: they tend to rise with age up to the age of 74 and then decrease for people older than 75 years old. This age pattern in inheritance receipt reflects both life-cycle and cohort effects but also to some extent may reflect a recall error bias. ${ }^{19}$ Since BHPS covers inheritances received during a ten year period the probability of having received an inheritance is much smaller than in AIS for all age groups with an estimated peak at 55-64 and marked decrease in the probability of inheriting after the age of 65. Given the time framework of inheritance data the age pattern in BHPS reflects more closely the age profiles of inheritance receipt. In other words the peak at the age group of 5564 which is observed in BHPS corresponds to the age group at which most people tend to receive an inheritance.

Despite some generic differences in the rate and the value of inheritance (which largely reflect differences in the time framework of the inheritance data covered by each survey) both surveys suggest a clear social gradient in the distribution of inheritance. In AIS the probability of inheriting rises from 32 per cent for people with no educational qualifications to about 58 per cent for people with degrees and from about 31 per cent for people in the lowest financial wealth class to about 66 per cent for people in highest financial wealth class; in the last ten years period covered by BHPS the probability of inheriting rises from about 11 per cent for people with no educational qualifications to about 29 per cent among those with degrees and from about 12 per cent for people in lowest financial wealth group to 31 per cent among those in highest financial wealth group. Also in both surveys the probability of inheriting is considerably higher amongst homeowners than non-homeowners (with a differential in the probability of inheriting between homeowners and tenants of about 20 percentage points in AIS and 11 percentage points in BHPS) and among higher income groups (although the relationship with income in both surveys are not as pronounced as in terms of the other characteristics). Clearly both financial wealth and homeownership are endogenous to inheritance since inheritors may have more chances of building up assets and entering the housing market. Although the size of inheritances shows that this is not the only factor at work the results should be interpreted with caution.

19 As stressed by Wolff (2002) the life cycle effects mainly reflect the fact that parents of older people are more likely to have died (increasing their likelihood of inheriting) while cohort effects reflect the fact that parents of older cohorts were more likely to be poorer than parents of younger cohorts of people. 
The patterns in terms of the value of inheritances are similar. Again strong differences are identified by educational level, financial wealth and home ownership status and to some extent income level. In AIS the mean value of inheritance is more than 100 per cent higher for people with degrees than for those with no qualifications, 400 per cent higher for people in the highest financial wealth class than for the lowest wealth class and 42 per cent higher for homeowners than for tenants (again due to the endogeneity the interpretation of the association with financial wealth and home ownership status is problematic). The patterns in BHPS are similar. The two main differences are that the differential by home ownership status is more pronounced than in AIS and that the association with education is weaker. In both surveys the value of inheritance tends to rise with income, but the association is either not strong or not so clear (as in median receipts). What is also clear from Table 6 is that the distribution of inheritances is highly skewed with few large inheritances and a large number of smaller ones. Both overall and within each of the groups we see mean receipts are several times higher than the medians. Finally, another thing to note from Table 6 is that although more advantaged socio-economic groups inherited more (both in terms of the probability and the value of inheritance), the absolute differences in the mean value of receipts was rather moderate - less than $£ 30,000$ in most cases (except from the much higher value of the highest financial wealth group which however is highly endogenous to inheritance) and less than $£ 7,000$ when we look at differences in the median value of inheritance. It is difficult to conceive that a difference of this or similar magnitude could result in any pronounced change in wealth inequality and/or social polarisation. ${ }^{20}$ Unarguably however, the pattern amplifies the absolute differences in resources across different socio-economic groups.

Because the differences in the average probability and value of inheritance across individuals grouped by income, education etc could be the result of differences in observable characteristics (especially when one considers the lifecycle aspects of inheritance receipt), it is necessary to analyse inheritance in a multivariate setting. To that end we estimate two types of models. The first is a simple probit regression predicting the probability of having received an inheritance while the second is an OLS regression explaining the logarithm of inheritance. Equations (1) and (2) describe the probit and OLS regressions respectively:

$$
\begin{array}{ll}
\mathrm{I}^{*}=\mathrm{X}_{i} \beta_{i}+\varepsilon_{i} & \mathrm{I}_{i}=1 \text { if } \mathrm{I}_{i}^{*}=0 \\
\mathrm{I}_{i}=0 \text { otherwise }
\end{array}
$$

$$
\mathrm{IW}_{i}=\mathrm{X}_{i} \beta_{i}+\varepsilon_{i}
$$

In equation (1) I indicates whether the respondent had received an inheritance, $I^{*}$ is the latent index determining whether the inheritance indicator (I) takes the value of zero or one, $\mathrm{X}$ is a vector of individual characteristics affecting the probability of directly. 
having received an inheritance, $\beta$ is a vector of parameters and $\varepsilon$ is an error term which we assume to follow a standard normal distribution. Equivalently in equation (2) IW is the $\log$ value of inheritance, $X$ is a vector of individual characteristics, $\beta$ is a vector of parameters and $\varepsilon$ is an error term.

For each of these two models we estimate three specifications. The baseline specification includes controls for respondents' age, educational attainment, and gross household income; the second specification adds controls for financial wealth and home ownership status (the two endogenous variables); while the final specification excludes financial wealth and homeownership status and adds dummies for parental background (five dummies indicating respondent's father's socio-economic class when the respondent was 14 years old). The first and second specifications are estimated using both data sets, while the third uses only data from BHPS. Table 7 and 8 reports the results from the probit and OLS models respectively. Because interpretation of the estimated coefficients from the probit model is not straightforward, in Table 8 we report marginal effects rather than the probit coefficients themselves. The reported results therefore can be interpreted as the percentage point difference in the probability of inheriting relative to the reference group. Since the dependent variable in equation (2) is the logarithm of the value of inheritance the coefficients from the OLS models can be interpreted as the percentage difference in the value of inheritance relative to the reference group.

Similarly to the descriptive analysis the estimates from the probit equations suggest a pronounced age profile in inheritance receipt (with BHPS suggesting a peak at the 5564 age group and AIS at the 65-74) and significant differences across the various socio-economic groups in the probability of receiving an inheritance. The positive effect of education and the fact that it remains strong in all specifications including those which introduce controls for parental socio-economic class (which can be seen as a proxy of parental wealth) is particularly noticeable. It suggests that parents who invest in their children's education are also more likely to bequeath wealth to their children. Significant differences are also identified across financial wealth groups and between homeowners and tenants. And although the estimates are slightly smaller than those suggested by the descriptive analysis they still seem to be of considerable size. $^{21}$

In line with the results from the descriptive analysis the OLS estimates suggest that the size of inheritance rises with socio-economic status. In many cases however, the estimated associations are considerably weaker than the bivariate ones. Particularly pronounced is the decrease in the effect of financial wealth and homeownership status. The main exception to this pattern is education which seems to retain most of its

21 In particular the estimates in Table 7 suggest a differential in the probability of inheriting between the lowest and highest financial wealth group of about 22 percentage points in AIS and 19 percentage points in BHPS. Similarly the estimated effects imply a differential in the probability of inheriting between homeowners and tenants of 7 percentage points in BHPS and 10 percentage points in AIS. Income is the only variable whose effects become much smaller and insignificant in statistical terms once other factors are controlled. 
predictive power once other factors are controlled for (significant associations are estimated in both AIS and BHPS although in the latter survey the estimated associations for the two mid educational groups are not so clear). Also, worth noting is that the value of inheritance increases with parental socio-economic status. Overall, the results from the multivariate analysis suggest that although inheritance is positively associated with socio-economic status the association is stronger in terms of the probability than in terms of the value of inheritance.

Given the trends in the rate and the value of inheritance that we documented earlier in the paper it seems important to consider whether the increases in the value of inheritance have strengthened or weakened the association between inheritance and socio-economic status. To address this question we pool data from GHS and BHPS (which include comparable data on larger inheritance for the time periods 1986-1995 and 1996-2005 respectively) and we estimate equations (1) and (2) with the addition of a set of interaction terms between socio-economic status with a period 1996-2005 dummy (i.e. the period of BHPS inheritance data). For each equation we estimate two specifications. The first includes age and education along with the interaction terms between education and time period while the second adds controls for homeownership status and the interaction terms between homeownership status and time. The coefficient on these interaction terms will capture changes in the effects of the each of the socio-economic status indicators over time. ${ }^{22}$ Results are reported in Table 9. As can be seen from this table the marginal effects on the interaction terms in the probit models are all positive, suggesting that the probability of receiving an inheritance increased more for the three higher educational groups than for the lowest one. In particular, according to the estimates the differential in inheritance probability between people with no qualifications and those with O-levels qualifications increased by about 5 percentage points while with the higher two education groups by about 2 percentage points. However, only the 5 percentage point differential between the lower and second lower educational group is significant. The marginal effect on the homeownership interaction dummy in the second specification is negative but insignificant suggesting that the difference in the probability of inheriting has not changed in any significant way for homeowner and non-homeowners. Similarly, the OLS estimates on the period education interaction terms are all positive implying that the disparities in the value of inheritance between people with no qualifications and all other educational groups have increased over time. However, the only effect that is significant is the effect on the interaction term for the highest educational group. Summarising the results of the interacted models suggests that the disparities in the probability and the value of inheritance between the lowest and the higher educational groups have increased over time and in some cases significantly. However, further

22 This approach assumes that the effect of other variables has not changed over time. One important issue of consideration is whether the estimates on the interaction terms are contaminated by measurement error in the dependent variables (the probability and the value of inheritance) especially given the retrospective nature of the GHS data. Assuming that measurement error is random (which we have no reason to believe is not) the estimates on the interaction terms will still be unbiased but their standard errors will be higher. 
comparisons across groups suggest a significant decrease in the disparities between the mid two educational groups.

All in all the results of this section suggest that inheritance is positively associated with socio-economic status. This association was stronger in terms of the probability than in terms of the value of inheritance especially once we control for differences in observed characteristics. The across-time comparisons based on GHS and BHPS data provide some suggestive evidence that the increase in the value of inheritance observed from the mid-1990s onwards benefited the middle and higher socioeconomic groups and significantly less the lowest group. This contrasts to popular assumptions that the increase in housing inheritance will have some equalising effects. However, it is in line with the conclusion of Hamnett (1991) who suggested that although housing inheritance will become more widespread this will mainly benefit mid and higher socio-economic groups while lowest socio-economic groups will be generally excluded from housing inheritance.

\section{Conclusions}

The central conclusion of this paper is that the size of inheritance has become more important over time and that housing inheritance has played an increasingly important role in the overall value of inheritance. Overall, according to data from the estate statistics during the $1985-2005$ period inheritance rose from $£ 22.2$ billion in 1984 to $£ 55.7$ billion by 2005 (with the most substantial increase observed after 2000). This took the flow of inheritance from being the equivalent of 3 per cent of GDP in 1984 to about 4.3 per cent in 2005 . This increase was largely driven by the increase in house prices and to a much lesser extent by the increase in the number of housing estates. The latter finding contrasts to the trends observed in earlier periods and seems to suggest that the spread in owner occupation started to feed into inheritance. The research also indicated that the distribution of inheritances is characterized by high degree of inequality. Over time comparisons based on data from the GHS and BHPS which cover the two ten year time period 1986-1995 and 1996-2005 respectively suggest that this has become more unequal over time. However, the inequalityincreasing effect from the greater inequality in the distribution of inheritance was counterbalanced by the increase in the percentage of the population who received inheritance of more than $£ 2,000$. The combined effect of the two trends was a slight decrease in the degree of inequality in the distribution of inheritance across the population as a whole in 1996-2005. Furthermore our analysis suggested that there is a positive association between inheritance and socio-economic status with some suggestive evidence that this association might have strengthened between 1986-1995 and 1996-2005. However, our evidence also indicates that there is a considerable heterogeneity in the population of inheritors and a large variation in the value of inheritance among them (with a few large inheritances and a large number of smaller ones). This result is not to suggest that inherited wealth does not reproduce (or even exaggerate) other types of socio-economic advantage but to stress the complexity of 
any analysis that attempts to quantify the effect of inheritances on the observed levels of wealth inequality.

Attempting to speculate about the potential impact of inheritance in the future we can argue that this would crucially depend on the change in the relative importance of other forms of wealth and the ability of households to accumulate wealth either through homeownership and/or through financial wealth. Although the magnitude of inheritance may increase the process will be rather slow and it is unlikely that this would result in any substantial change in wealth accumulation for the majority of households (except from the very rich i.e. top 1-5 per cent of the population). Policies that promote the ability of households to accumulate wealth via homeownership or through ownership of financial assets should be at the heart of policies that aim to increase the wealth holdings of the population (especially given the increased needs to fund retirement which arises from the increases in life expectancy). Under the current structure of the Inheritance Tax in the UK Inheritance Tax is paid on an individual's estates when it is passed on death. No tax is paid on estates smaller than a given threshold the 'nil rate band threshold' (set at $£ 325,000$ in 2011-12) while a single tax rate of 40 percent is charged for the amount above this threshold (transfers between spouses are exempt for IHT). Since October 2007, married couples and registered civil partners can effectively increase the 'nil rate band threshold' on their estate when the second partner dies - to as much as $£ 650,000$ in 2011-12 (HMRC, 2011b). Given the current structure, only a minority of very wealthy estates are liable to Inheritance Tax (in 2007-08 tax paying estates represented only about 8 per cent of all estates). Any increase in the Inheritance Tax threshold would represent a reallocation of wealth to the very wealthy. Moving from the current Estate Tax to an Inheritance Tax which linked tax to the situation of the recipient would be fairer from a redistributive point of view. 


\section{References}

Becker, G. S., and N. Tomes (1979), 'An Equilibrium Theory of the Distribution of Income and Intergenerational Mobility,' Journal of Political Economy, 87(6), 1153-1189.

Davies, J.B., (1982), 'The relative impact of inheritance and other factors on economic inequality', Quarterly Journal of Economics, 97(3), 471-498.

Davies, J. B., and A. F. Shorrocks (2000), 'The Distribution of Wealth', in Handbook of Income Distribution, ed. by A. B. Atkinson and F. Bourguignon, vol. 1, Elsevier: Amsterdam, 605-675.

De Nardi, M. (2004), 'Wealth Inequality and Intergenerational Links', Review of Economic Studies, 71, 743-768.

Gale, W. G., and J. K. Scholz (1994), 'Intergenerational Transfers and the Accumulation of Wealth,' Journal of Economic Perspectives, 8(4), 145-160.

Gokhale, J., Kotlikoff, L., Sefton, J. and Weale, M. (2001), 'Simulating the transmission of wealth inequality via bequests', Journal of Public Economics, 79, 93-128.

Hamnett, C. (1991), 'A nation of inheritors? Housing inheritance, wealth and inequality in Britain', Journal of Social Policy, 20, 509-36.

Hamnett, C. (1992), 'The Geography of Housing Wealth and Inheritance in Britain', The Geographical Journal, 158(3).

Hamnett, C., Harmer, M. and Williams, P. (1991), Safe as houses: Housing inheritance in Britain. London: Paul Chapman.

Harbury, C.D. (1962), 'Inheritance and the distribution of wealth in Britain', Economic Journal, 72, 845-868.

Harbury, C.D. and D.M.W.N. Hitchens (1976), ; The inheritance of top wealth leavers: Some further evidence', Economic Journal, 86, 321-326.

Harbury, C.D. and D.M.W.N. Hitchens (1979), Inheritance and Wealth Inequality in Britain. London: George Allen and Unwin.

Harbury, C.D. and P.C.McMahon (1973), 'Inheritance and the characteristics of top wealth leavers in Britain', Economic Journal, 83, 810-833.

HM Revenue and Customs (2011a), Description of inheritance tax, HM Revenue and Customs http://www.hmrc.gov.uk/stats/inheritance_tax/description-of-tax.pdf

HM Revenue and Customs (2011b),Inheritance Tax- The basics, HM Revenue and Customs http://www.hmrc.gov.uk/inheritancetax/intro/basics.htm

Holmans, A. (1997) 'Housing and Inheritance Revisited', Housing Finance, 33(February).

Holmans, A. (2008) Prospects for UK Housing Wealth and Inheritance. London: Council of Mortgage Lenders. 
Holmans, A.E., and M. Frosztega (1994), House Property and Inheritance in the UK. London: HMSO.

Kotlikoff, Laurence J., and Lawrence H. Summers (1981), 'The Role of Intergenerational Transfers in Aggregate Capital Accumulation,' Journal of Political Economy, August 1981, 89, 706-32.

Kotlikoff, L.J., and L.H. Summers (1988), 'The Contribution of Intergenerational Transfers to Total Wealth: A Reply.' In Kessler, Denis, and Andre Masson, eds., Modelling the Accumulation and Distribution of Wealth. Oxford: Clarendon Press, 53-67.

Klevmarken, A. N. (2004), 'On the wealth dynamics of Swedish families, 1984-98', Review of Income and Wealth, 50, 4.

Laitner, J., (1979a), 'Household bequests, perfect expectations, and the national distribution of wealth', Econometrica, 47(5), 1175-1193.

Laitner, J., (1979b), 'Household bequest behaviour and the national distribution of wealth', Review of Economic Studies, 46(3), 467-483.

Lloyd, J. (2008), Navigating the Age of Inheritance. London: ILC.

Modigliani, F. (1988a), 'Measuring the Contribution of Intergenerational Transfers to Total Wealth: Conceptual Issues and Empirical Findings.' In Kessler, Denis, and Andre Masson, eds., Modelling the Accumulation and Distribution of Wealth. Oxford: Clarendon Press, 21-52.

Modigliani, F. (1988b), 'The Role of Intergenerational Transfers and Life Cycle Saving in the Accumulation of Wealth,' Journal of Economic Perspectives, Spring(2), 15-40.

Piketty, T. (2011), 'On the Long-Run Evolution of Inheritance: France 1820-2050', Quarterly Journal of Economics, forthcoming

Ross, A, Lloyd, J. and Weinhardt, M. (2008), The age of inheritance. London: ILCUK.

Rowlingson, K. McKay, S. (2005), Attitudes to inheritance in Britain. Bristol: The Policy Press.

Royal Commission (1977), Royal Commission on the Distribution of Income and Wealth, Report No. 5. Third Report on the Standing Reference. London: HMSO.

Smith, J. P., (1999), 'Inheritances and Bequests', in F. Welch (ed.) Increasing Income Inequalities in America: The Facts, Causes and Consequences. Chicago: University of Chicago Press.

Stiglitz, J (1969), 'Distribution of Wealth among individuals', Econometrica, 37(3), 382-397

Tomes, N. (1981), 'The family, inheritance, and the intergenerational transmission of inequality', Journal of Political Economy, 89 (5), 928-958. 
Wolff, E.N. (2002), 'Bequests, savings and wealth inequality', American Economic Association Paper and Proceedings, 92(2), pp. 260-4.

Wedgwood, J. (1928), 'The influence of inheritance on the distribution of wealth', Economic Journal, 38: 38-55.

Wedgwood, J. (1929), The Economics of Inheritance. London: George Routledge \& Sons. 
Table 1: Statistics on estates passing on death by year of death, United Kingdom, all estates and by type

\begin{tabular}{|c|c|c|c|c|c|c|c|c|c|}
\hline \multirow[b]{2}{*}{ Year } & \multicolumn{3}{|c|}{$\begin{array}{c}\text { Number of estates } \\
\text { (thousands) }\end{array}$} & \multicolumn{3}{|c|}{$\begin{array}{l}\text { Total value of estates } \\
\text { (billion } £, 2005 \text { prices) }\end{array}$} & \multicolumn{3}{|c|}{$\begin{array}{c}\text { Mean value of estate } \\
\text { (thousand } £, 2005 \text { prices) }\end{array}$} \\
\hline & $\begin{array}{c}\text { Financial } \\
\text { assets }\end{array}$ & $\begin{array}{l}\text { Housing } \\
\text { assets }\end{array}$ & $\begin{array}{c}\text { All } \\
\text { estates }\end{array}$ & $\begin{array}{l}\text { Financial } \\
\text { estates }\end{array}$ & $\begin{array}{c}\text { Housing } \\
\text { estates }\end{array}$ & $\begin{array}{c}\text { All } \\
\text { estates }\end{array}$ & $\begin{array}{c}\text { Financial } \\
\text { estates }\end{array}$ & $\begin{array}{l}\text { Housing } \\
\text { estates }\end{array}$ & $\begin{array}{c}\text { All } \\
\text { estates }\end{array}$ \\
\hline $1984 / 85$ & 272.9 & 154.6 & 273.8 & 12.3 & 9.8 & 22.2 & 45.3 & 63.5 & 81.0 \\
\hline $1985 / 86$ & 244.1 & 143.2 & 245.1 & 13.2 & 10.0 & 23.2 & 54.2 & 69.7 & 94.7 \\
\hline $1986 / 87$ & 270.5 & 154.1 & 270.9 & 14.0 & 10.9 & 24.9 & 51.7 & 71.0 & 92.0 \\
\hline $1987 / 88$ & 233.7 & 130.4 & 234.7 & 14.8 & 12.1 & 26.9 & 63.3 & 93.0 & 114.6 \\
\hline $1988 / 89$ & 247.6 & 144.5 & 249.2 & 15.0 & 15.5 & 30.5 & 60.4 & 107.5 & 122.3 \\
\hline $1989 / 90$ & 270.9 & 158.7 & 276.4 & 16.7 & 16.2 & 32.9 & 61.6 & 102.1 & 119.0 \\
\hline $1990 / 91$ & 248.8 & 142.8 & 252.4 & 14.6 & 13.2 & 27.8 & 58.6 & 92.5 & 110.1 \\
\hline $1991 / 92$ & 251.6 & 147.3 & 255.2 & 15.5 & 12.4 & 27.8 & 61.5 & 83.9 & 109.1 \\
\hline $1992 / 93$ & 250.6 & 146.3 & 254.4 & 15.7 & 11.5 & 27.2 & 62.8 & 78.6 & 107.0 \\
\hline $1993 / 94$ & 282.7 & 164.8 & 285.1 & 17.9 & 12.4 & 30.4 & 63.5 & 75.5 & 106.6 \\
\hline $1994 / 95$ & 268.9 & 154.2 & 270.9 & 17.1 & 11.8 & 28.9 & 63.7 & 76.7 & 106.9 \\
\hline $1995 / 96$ & 284.0 & 158.5 & 285.1 & 18.7 & 11.4 & 30.1 & 65.8 & 72.1 & 105.6 \\
\hline $1996 / 97$ & 284.3 & 157.2 & 285.9 & 19.7 & 12.0 & 31.7 & 69.4 & 76.2 & 110.9 \\
\hline $1997 / 98$ & 255.7 & 148.2 & 256.9 & 19.4 & 11.8 & 31.2 & 75.8 & 80.0 & 121.5 \\
\hline $1998 / 99$ & 273.5 & 154.6 & 274.8 & 21.8 & 13.2 & 35.0 & 79.6 & 85.5 & 127.3 \\
\hline $1999 / 00$ & 282.4 & 164.1 & 283.8 & 23.9 & 16.3 & 40.1 & 84.5 & 99.1 & 141.4 \\
\hline \multicolumn{10}{|l|}{$2000 / 01$} \\
\hline \multicolumn{10}{|l|}{$2001 / 02$} \\
\hline $2002 / 03$ & 279.7 & 175.1 & 282.7 & 23.9 & 24.7 & 48.6 & 85.6 & 140.9 & 172.0 \\
\hline $2003 / 04$ & 283.5 & 180.3 & 285.7 & 24.5 & 28.4 & 52.9 & 86.4 & 157.6 & 185.2 \\
\hline \multicolumn{10}{|l|}{$2004 / 05$} \\
\hline $2005 / 06$ & 271.8 & 177.3 & 273.0 & 25.6 & 30.1 & 55.7 & 94.3 & 169.7 & 204.1 \\
\hline
\end{tabular}

Notes: The statistics are based on all estates passing on death including spousal estates. The mean value of estates reported in the last panel of the table is computed by dividing the total value of estates with the total number of estates. Source: Own analysis based on HMRC Inheritance tax statistics (Inland Revenue aggregate statistics, various years). 
Figure 1: Statistics on estates passing on death 1984/85-2005/06

1.a Number of estates, millions

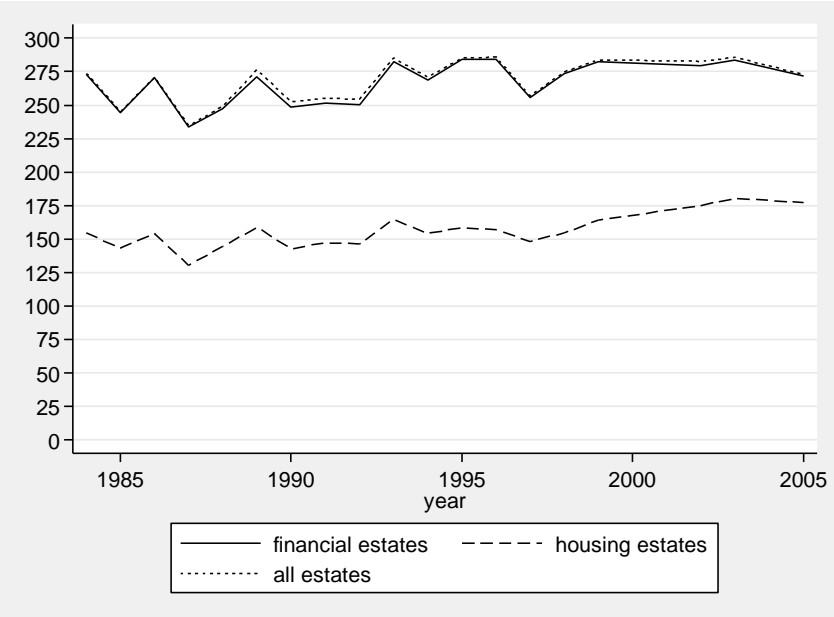

1.c Mean value of estates, thousand $£, 2005$ prices

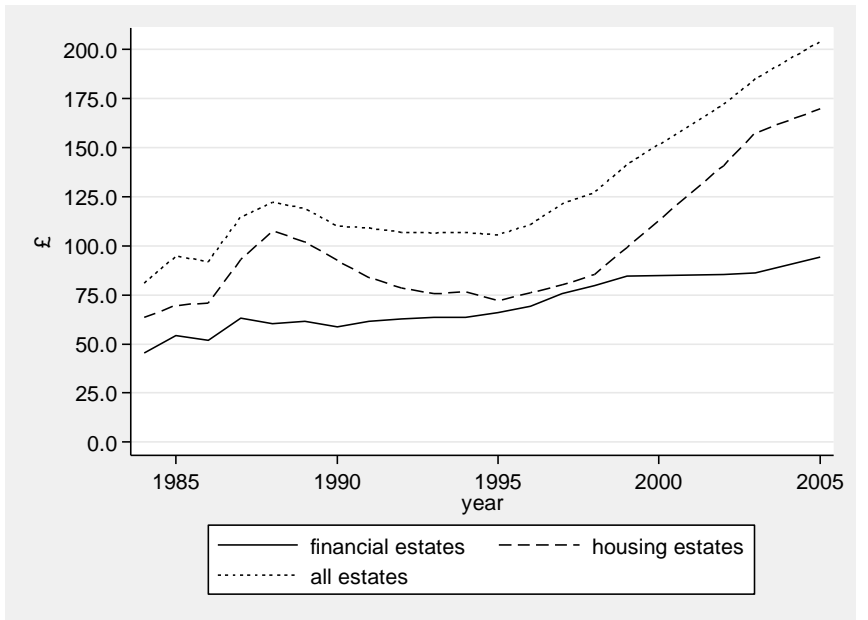

1.b Total value of estates, billion $£, 2005$ prices

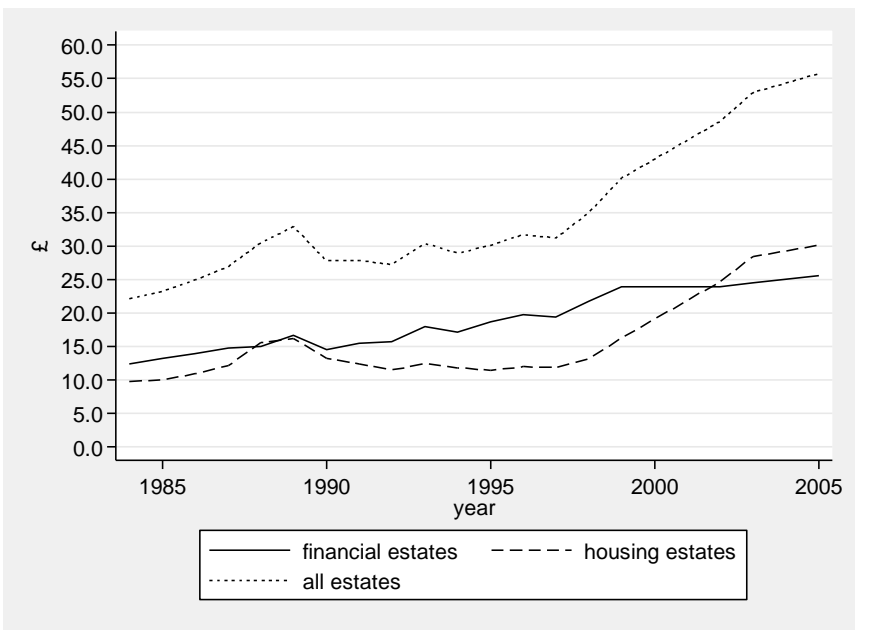

1.d Real house prices, 1985-2005 (price adjusted-2005=100)

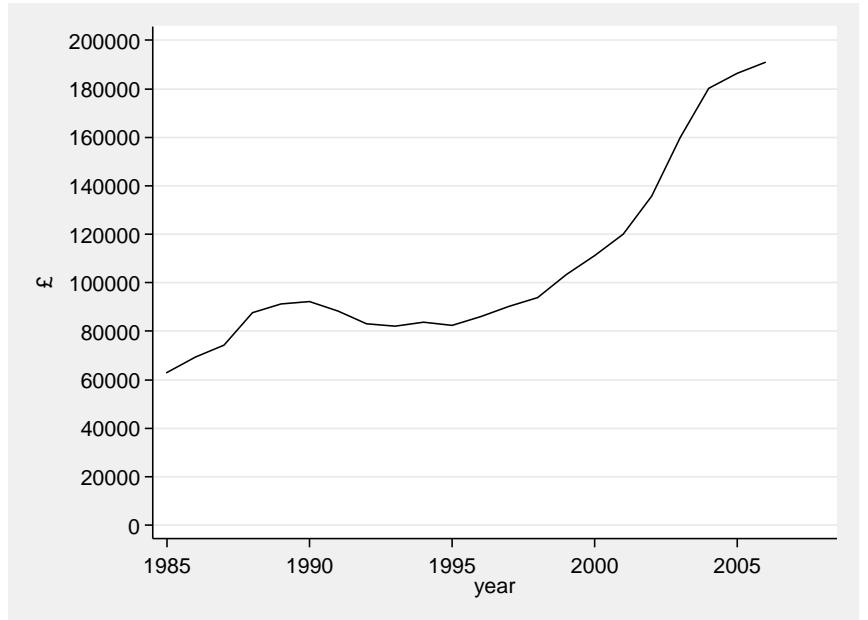

Note: The estates statistics presented in this figures are based on own analysis based on HMRC Inheritance tax statistics. Note that the estate statistics for 2003 and 2005 were kindly provided on request by HMRC. The source for the house prices statistics is Table 502 Housing market: House prices since 1930, UK (accessed from Communities and Local Government website: http://www.communities.gov.uk/documents/housing/xls/141272.xls). 
Table 2:The number and the value of 'non-spousal' estates passing on death by year of death, United Kingdom

\begin{tabular}{|c|c|c|c|}
\hline Year & $\begin{array}{l}\text { Number of 'non- } \\
\text { spousal estates' } \\
\text { (thousands) }\end{array}$ & $\begin{array}{l}\text { Total value 'non- } \\
\text { spousal estates' } \\
\text { (billion } £, 2005 \\
\text { prices) }\end{array}$ & $\begin{array}{c}\text { Mean value of 'non- } \\
\text { spousal estates' } \\
\text { estates } \\
\text { (thousand } £, 2005 \\
\text { prices) }\end{array}$ \\
\hline 1986 & 198.7 & 17.7 & 89.0 \\
\hline 1987 & 165.6 & 18.3 & 110.3 \\
\hline 1988 & 183.5 & 20.8 & 113.6 \\
\hline 1989 & 199.6 & 22.3 & 111.7 \\
\hline 1990 & 184.0 & 19.1 & 103.6 \\
\hline 1991 & 186.6 & 19.3 & 103.6 \\
\hline 1992 & 185.7 & 18.7 & 100.7 \\
\hline 1993 & 206.8 & 21.2 & 102.7 \\
\hline 1994 & 197.2 & 20.2 & 102.4 \\
\hline \multicolumn{4}{|l|}{1995} \\
\hline 1996 & 199.9 & 21.9 & 109.7 \\
\hline 1997 & 179.7 & 21.7 & 120.6 \\
\hline 1998 & 198.7 & 24.3 & 122.4 \\
\hline 1999 & 198.1 & 27.8 & 140.2 \\
\hline \multicolumn{4}{|l|}{2000} \\
\hline \multicolumn{4}{|l|}{2001} \\
\hline 2002 & 200.3 & 33.4 & 166.9 \\
\hline 2003 & 219.3 & 38.4 & 175.0 \\
\hline \multicolumn{4}{|l|}{2004} \\
\hline 2005 & 202.1 & 39.3 & 194.6 \\
\hline
\end{tabular}

Notes: Statistics are based on all estates passing on death excluding the estimated 'spousal estates' (see text for details). The mean value of estates reported in the last panel of the table is computed by dividing the total value of estates with the total number of estates.

Source: Own analysis based on HMRC Inheritance Tax statistics (Inland Revenue aggregate statistics, various years). Inheritance statistics for 2003 and 2005 were kindly provided on request by HMRC. 
Table 3: Annual inheritance rate and mean value of inheritance, 1986-2005 (excluding spousal inheritance)

\begin{tabular}{|c|c|c|c|c|}
\hline & \multicolumn{2}{|c|}{$\begin{array}{c}\text { All inheritance greater } \\
\text { than } £ 2,000 \text { in constant } \\
2005 \text { prices }\end{array}$} & \multicolumn{2}{|c|}{ All inheritances } \\
\hline & GHS & BHPS & AIS & BHPS \\
\hline \multicolumn{5}{|l|}{$\begin{array}{l}\text { Average annual inheritance rate } \\
(\%)\end{array}$} \\
\hline 1986-1990 & 0.8 & & & \\
\hline 1991-1995 & 1.2 & & 1.9 & \\
\hline 1996-2000 & & 1.4 & 2.2 & 2.5 \\
\hline 2001-2005 (2001-2004 for AIS) & & 1.4 & 2.2 & 2.4 \\
\hline \multicolumn{5}{|l|}{$\begin{array}{l}\text { Mean value of inheritance ( } £ \text { in } \\
2004 \text { prices) }\end{array}$} \\
\hline $1986-1990$ & 34,100 & & & \\
\hline 1991-1995 & 27,200 & & 18,500 & \\
\hline $1996-2000$ & & 31,300 & 28,500 & 20,900 \\
\hline 2001-2005 (2001-2004 for AIS) & & 38,200 & 34,200 & 27,500 \\
\hline
\end{tabular}

Note: Figures in AIS and GHS have been adjusted to account for the potential bias which may arise from the fact that some of the inheritors may have died between the time of receipt of inheritance and the interview. All figures are rounded to the nearest $£ 100$. The value of estates in earlier years is converted to 2005 prices, using the Retail Price Index.

Source: Own analysis using the 1995/96 General Household Survey, the Attitudes to Inheritances Survey and the British Household Panel Survey (waves 7-16). 
Table 4: The distribution of inheritances by type (excluding spousal inheritance)

\begin{tabular}{|c|c|c|c|c|c|c|}
\hline & \multicolumn{3}{|c|}{ Attitudes to Inheritances Survey } & \multicolumn{3}{|c|}{ General Household Survey } \\
\hline & $\begin{array}{c}\text { Only } \\
\text { housing }\end{array}$ & $\begin{array}{l}\text { Only } \\
\text { other } \\
\text { assets }\end{array}$ & $\begin{array}{c}\text { Both } \\
\text { housing } \\
\text { and other } \\
\text { assets }\end{array}$ & $\begin{array}{l}\text { Only } \\
\text { housing }\end{array}$ & $\begin{array}{l}\text { Only other } \\
\text { assets }\end{array}$ & $\begin{array}{c}\text { Both } \\
\text { housing and } \\
\text { other assets }\end{array}$ \\
\hline \multicolumn{7}{|c|}{$\begin{array}{l}\% \text { receiving each type } \\
\text { annually }\end{array}$} \\
\hline $1986-90$ & & & & 0.26 & 0.40 & 0.10 \\
\hline $1991-95$ & 0.08 & 1.48 & 0.24 & 0.34 & 0.62 & 0.16 \\
\hline 1996-00 & 0.12 & 1.54 & 0.40 & & & \\
\hline 2001-04 & 0.13 & 1.72 & 0.30 & & & \\
\hline \multicolumn{7}{|c|}{ Mean value by type (f) } \\
\hline $1986-90$ & & & & 36,500 & 15,800 & 67,300 \\
\hline $1991-95$ & $20,400 *$ & 20,400 & 80,500 & 24,600 & 12,800 & 65,300 \\
\hline 1996-00 & $82,800 *$ & 16,000 & 104,400 & & & \\
\hline 2001-04 & $61,300 *$ & 20,100 & 159,600 & & & \\
\hline
\end{tabular}

Note: Includes all inheritances reported by GHS respondents (i.e. including those valued less than $£ 2,000$ in real 2005 prices). For BHPS, the figures for 1996-2000 and 2001-2005 are for five years starting in last quarter of 1996 and of 2001 respectively. All figures are rounded to the nearest $£ 100$. Source: Own analysis using the 1995/96 General Household Survey and the Attitudes to Inheritances Survey. *Based on a sample of less than 15 observations. 
Table 5: Various statistics describing the distribution of inheritances in the UK for individuals (all inheritances are expressed in 2005 prices)

\begin{tabular}{|c|c|c|c|c|}
\hline & \multicolumn{2}{|c|}{ All inheritances } & \multicolumn{2}{|c|}{$\begin{array}{c}\text { All inheritance above } \\
£ 2000 \text { in constant } 2005 \\
\text { prices }\end{array}$} \\
\hline & AIS & BHPS & GHS & BHPS \\
\hline \multicolumn{5}{|l|}{ All respondents } \\
\hline$\%$ of inheritors & 43.9 & 19.5 & 8.4 & 12.5 \\
\hline $\mathrm{P} 25$ & 0 & 0 & 0 & 0 \\
\hline P50 & 0 & 0 & 0 & 0 \\
\hline P75 & 4,100 & 0 & 0 & 0 \\
\hline P90 & 37,400 & 5,100 & 0 & 5,100 \\
\hline P95 & 87,000 & 28,200 & 11,400 & 28,200 \\
\hline P99 & 311,000 & 146,900 & 76,000 & 146,900 \\
\hline Mean & 16,500 & 6,000 & 3,000 & 6,000 \\
\hline Gini & 0.90 & 0.96 & 0.97 & 0.96 \\
\hline \multicolumn{5}{|l|}{ Inheritors only } \\
\hline P25 & 2,300 & 1,900 & 6,000 & 5,800 \\
\hline P50 & 9,400 & 7,600 & 16,000 & 16,800 \\
\hline P75 & 38,000 & 36,100 & 41,900 & 52,900 \\
\hline P90 & 107,400 & 98,900 & 85,800 & 125,000 \\
\hline P95 & 209,200 & 156,300 & 116,100 & 191,700 \\
\hline P99 & 441,700 & 353,900 & 234,000 & 431,900 \\
\hline Mean & 42,200 & 35,000 & 35,100 & 47,800 \\
\hline Gini & 0.75 & 0.74 & 0.62 & 0.66 \\
\hline \multicolumn{5}{|c|}{$\%$ of inheritance received by } \\
\hline Top $1 \%$ of inheritors & 12 & 14 & 11 & 12 \\
\hline Top 5\% of inheritors & 42 & 40 & 29 & 34 \\
\hline Top $10 \%$ of inheritors & 62 & 58 & 44 & 50 \\
\hline
\end{tabular}

Note: In the analysis of this table we exclude three outlier observations in GHS that are above $£ 1,000,000$. This exclusion was made in order to increase comparability across the surveys since different surveys have different degree of accuracy over the top of the distribution of inheritance. 
Table 6: The percentage of individuals who received inheritances of any financial value and mean and median value of inheritance by various characteristics (excluding spousal inheritances)

\begin{tabular}{|c|c|c|c|c|c|c|}
\hline & \multicolumn{2}{|c|}{$\%$ inheriting } & \multicolumn{2}{|c|}{$\begin{array}{l}\text { Mean value of } \\
\text { inheritance }\end{array}$} & \multicolumn{2}{|c|}{$\begin{array}{l}\text { Median value of } \\
\text { inheritance }\end{array}$} \\
\hline & AIS & BHPS & AIS & BHPS & AIS & BHPS \\
\hline All adults aged over 25 & 43.9 & 19.5 & 42,100 & 35,000 & 9,400 & 7,600 \\
\hline \multicolumn{7}{|l|}{ Age group } \\
\hline $25-34$ & 35.6 & 16.2 & 13,500 & 12,300 & 3,100 & 2,300 \\
\hline $35-44$ & 41.8 & 19.1 & 22,800 & 28,200 & 4,100 & 5,100 \\
\hline $45-54$ & 47.5 & 21.3 & 56,700 & 39,800 & 11,700 & 11,200 \\
\hline $55-64$ & 49.3 & 26.9 & 52,300 & 44,200 & 15,400 & 13,000 \\
\hline $65-74$ & 48.9 & 19.8 & 52,200 & 42,200 & 18,600 & 10,800 \\
\hline $75+$ & 36.4 & 8.3 & 45,700 & 36,100 & 16,000 & 5,600 \\
\hline \multicolumn{7}{|l|}{ Education } \\
\hline None & 32.0 & 10.7 & 23,700 & 26,400 & 7,100 & 5,300 \\
\hline GCSE O level or lower & 42.4 & 19.0 & 39,300 & 41,500 & 7,700 & 9,800 \\
\hline Higher qualification-A level & 51.4 & 21.2 & 53,100 & 30,200 & 11,200 & 7,100 \\
\hline Degree or equivalent & 58.2 & 29.3 & 52,600 & 44,700 & 15,200 & 10,900 \\
\hline \multicolumn{7}{|l|}{ Weekly gross household income } \\
\hline$£ 0-199$ & 38.4 & 16.4 & 35,200 & 27,100 & 6,000 & 5,400 \\
\hline$£ 200-399$ & 49.8 & 16.3 & 36,600 & 36,400 & 10,500 & 7,600 \\
\hline$£ 400-999$ & 51.6 & 20.3 & 46,600 & 33,900 & 9,400 & 7,500 \\
\hline$>£ 1000$ & 47.0 & 24.9 & 52,900 & 40,100 & 13,700 & 9,900 \\
\hline \multicolumn{7}{|l|}{ Home ownership status } \\
\hline Non home owners & 29.3 & 10.9 & 30,700 & 18,100 & 3,800 & 4,400 \\
\hline Home owners & 48.9 & 21.9 & 44,500 & 37,500 & 10,900 & 8,800 \\
\hline \multicolumn{7}{|l|}{ Gross financial wealth level $(£)$} \\
\hline Wealth is missing & 39.4 & 15.0 & 32,700 & 22,600 & 8,300 & 3,500 \\
\hline $0-999$ & 30.8 & 11.7 & 22,700 & 12,800 & 3,400 & 4,000 \\
\hline $1,000-4,999$ & 41.5 & 16.5 & 18,800 & 25,200 & 6,700 & 4,700 \\
\hline $5,000-9,999$ & 44.8 & 20.4 & 17,000 & 17,200 & 6,700 & 4,800 \\
\hline $10,000-49,999$ & 52.1 & 22.9 & 44,600 & 40,900 & 15,200 & 10,600 \\
\hline $50,000-99,999$ & 66.9 & 28.7 & 60,000 & 51,400 & 25,500 & 27,300 \\
\hline More than 100,000 & 65.8 & 31.2 & 121,600 & 65,800 & 43,300 & 22,400 \\
\hline $\mathrm{N}$ who received inheritances & 798 & 1,098 & & & & \\
\hline $\mathrm{N}$ & 1,820 & 5,637 & & & & \\
\hline
\end{tabular}

Note: Since some respondents have received more than one inheritance during this period the percentage of inheritors is less than the one implied by the annual inheritance rate.

Source: Own analysis of data from the BHPS (waves7-16) and the AIS (2004). 
Table 7: Probit marginal effects of the association between socio-economic status and the probability of inheriting

\begin{tabular}{|c|c|c|c|c|c|}
\hline \multirow{3}{*}{$\begin{array}{l}\text { Age group ref. 25-34 } \\
35-44\end{array}$} & \multicolumn{2}{|c|}{ AIS } & \multicolumn{3}{|c|}{ BHPS } \\
\hline & & & & & \\
\hline & $\begin{array}{l}0.08 * * \\
(0.04)\end{array}$ & $\begin{array}{l}0.05 \\
(0.04)\end{array}$ & $\begin{array}{l}0.03 * \\
(0.02)\end{array}$ & $\begin{array}{c}0.01 \\
(0.02)\end{array}$ & $\begin{array}{c}0.03 \\
(0.02)\end{array}$ \\
\hline $45-54$ & $\begin{array}{c}0.17 * * * \\
(0.04)\end{array}$ & $\begin{array}{c}0.12^{* * * *} \\
(0.04)\end{array}$ & $\begin{array}{c}0.07 * * * \\
(0.02)\end{array}$ & $\begin{array}{c}0.02 \\
(0.02)\end{array}$ & $\begin{array}{c}0.06 * * * * \\
(0.02)\end{array}$ \\
\hline $55-64$ & $\begin{array}{c}0.22 * * * \\
(0.04)\end{array}$ & $\begin{array}{c}0.13^{* * * *} \\
(0.05)\end{array}$ & $\begin{array}{c}0.15^{* * * *} \\
(0.02)\end{array}$ & $\begin{array}{c}0.07 * * * \\
(0.02)\end{array}$ & $\begin{array}{c}0.15^{* * * *} \\
(0.03)\end{array}$ \\
\hline $65-74$ & $\begin{array}{c}0.26 * * * \\
(0.04)\end{array}$ & $\begin{array}{c}0.15^{* * * *} \\
(0.05)\end{array}$ & $\begin{array}{c}0.11 * * * \\
(0.03)\end{array}$ & $\begin{array}{c}0.02 \\
(0.03)\end{array}$ & $\begin{array}{c}0.11 * * * \\
(0.03)\end{array}$ \\
\hline \multicolumn{6}{|l|}{ Education ref. None } \\
\hline GCSE O level or lower & $\begin{array}{c}0.13 * * * \\
(0.03)\end{array}$ & $\begin{array}{l}0.09 * * \\
(0.04)\end{array}$ & $\begin{array}{c}0.11 * * * \\
(0.03)\end{array}$ & $\begin{array}{c}0.08 * * * \\
(0.02)\end{array}$ & $\begin{array}{c}0.10 * * * \\
(0.03)\end{array}$ \\
\hline At least one A level & $\begin{array}{c}0.23 * * * \\
(0.04)\end{array}$ & $\begin{array}{c}0.17 * * * \\
(0.04)\end{array}$ & $\begin{array}{c}0.13 * * * \\
(0.02)\end{array}$ & $\begin{array}{c}0.09 * * * \\
(0.02)\end{array}$ & $\begin{array}{c}0.11 * * * \\
(0.02)\end{array}$ \\
\hline Degree or equivalent & $\begin{array}{c}0.30 * * * \\
(0.04)\end{array}$ & $\begin{array}{c}0.25^{* * * *} \\
(0.04)\end{array}$ & $\begin{array}{c}0.23 * * * \\
(0.03)\end{array}$ & $\begin{array}{c}0.17 * * * \\
(0.03)\end{array}$ & $\begin{array}{c}0.18 * * * \\
(0.03)\end{array}$ \\
\hline \multicolumn{6}{|c|}{ Household income ref.£0-299 } \\
\hline$£ 300-499$ & $\begin{array}{c}0.03 \\
(0.04)\end{array}$ & $\begin{array}{l}-0.03 \\
(0.04)\end{array}$ & $\begin{array}{l}-0.03 \\
(0.02)\end{array}$ & $\begin{array}{l}-0.04 * \\
(0.02)\end{array}$ & $\begin{array}{l}-0.03 \\
(0.02)\end{array}$ \\
\hline$£ 500-999$ & $\begin{array}{l}0.09 * * \\
(0.04)\end{array}$ & $\begin{array}{l}-0.01 \\
(0.05)\end{array}$ & $\begin{array}{l}-0.01 \\
(0.02)\end{array}$ & $\begin{array}{l}-0.04 * \\
(0.02)\end{array}$ & $\begin{array}{l}-0.01 \\
(0.02)\end{array}$ \\
\hline$>£ 1000$ & $\begin{array}{l}-0.02 \\
(0.05)\end{array}$ & $\begin{array}{c}-0.16 * * * * \\
(0.05)\end{array}$ & $\begin{array}{c}0.01 \\
(0.03)\end{array}$ & $\begin{array}{l}-0.04 * \\
(0.02)\end{array}$ & $\begin{array}{c}0.00 \\
(0.03)\end{array}$ \\
\hline \multicolumn{6}{|l|}{ Homeownership status } \\
\hline Homeowners & & $\begin{array}{c}0.10^{* * * *} \\
(0.03)\end{array}$ & & $\begin{array}{c}0.07 * * * \\
(0.01)\end{array}$ & \\
\hline \multicolumn{6}{|c|}{ Gross financial wealth, ref. $<£ 1000$} \\
\hline $1,000-4,999$ & & $\begin{array}{l}0.08 * \\
(0.05)\end{array}$ & & $\begin{array}{l}0.05^{* *} \\
(0.02)\end{array}$ & \\
\hline $5,000-9,999$ & & $\begin{array}{c}0.06 \\
(0.05)\end{array}$ & & $\begin{array}{c}0.08 * * * \\
(0.03)\end{array}$ & \\
\hline $10,000-49,999$ & & $\begin{array}{l}0.11 * * \\
(0.04)\end{array}$ & & $\begin{array}{c}0.11 * * * \\
(0.02)\end{array}$ & \\
\hline $50,000-99,999$ & & $\begin{array}{c}0.23 * * * \\
(0.06)\end{array}$ & & $\begin{array}{c}0.15 * * * \\
(0.03)\end{array}$ & \\
\hline More than 100,000 & & $\begin{array}{c}0.22 * * * \\
(0.06)\end{array}$ & & $\begin{array}{c}0.19 * * * \\
(0.03)\end{array}$ & \\
\hline \multicolumn{6}{|l|}{ Father's s.e. class ref. Prof. } \\
\hline Inter. -skilled non-manual & & & & & $\begin{array}{c}-0.07 * * * \\
(0.02)\end{array}$ \\
\hline Skilled manual & & & & & $\begin{array}{c}-0.10 * * * \\
(0.02)\end{array}$ \\
\hline Partly skilled or unskilled & & & & & $\begin{array}{c}-0.16^{* * * * *} \\
(0.02)\end{array}$ \\
\hline Number of Obs. & 1623 & 1623 & 4955 & 4955 & 4955 \\
\hline Pseudo R-squared & 0.046 & 0.062 & 0.026 & 0.045 & 0.038 \\
\hline Log-likelihood & -1063.9 & -1046.9 & -2479.1 & -2430.2 & -2450.28 \\
\hline
\end{tabular}

Note: The sample includes all respondents aged 25-74 years old. Standard errors are reported in parentheses. $* * *$ indicates coefficient statistically significant at the $1 \%$ level, $* *$ at the $5 \%$ level and * at the 10\% level. Source: Own analysis of data from the BHPS (waves7-16) and the AIS (2004). 
Table 8: OLS estimates of the association between the value of inheritance and socio-economic status

\begin{tabular}{|c|c|c|c|c|c|}
\hline \multirow{2}{*}{ Age group ref. 25-34 } & \multicolumn{2}{|c|}{ AIS } & \multicolumn{3}{|c|}{ BHPS } \\
\hline & & & & & \\
\hline \multirow[t]{2}{*}{$35-44$} & 0.32 & 0.17 & $0.48 * *$ & 0.34 & $0.49 * *$ \\
\hline & $(0.24)$ & $(0.24)$ & $(0.22)$ & $(0.22)$ & $(0.24)$ \\
\hline \multirow[t]{2}{*}{$45-54$} & $1.30 * * *$ & $0.98 * * *$ & $1.14 * * *$ & $0.83 * * *$ & $1.15 * * *$ \\
\hline & $(0.24)$ & $(0.25)$ & $(0.22)$ & $(0.22)$ & $(0.24)$ \\
\hline \multirow[t]{2}{*}{$55-64$} & $1.60 * * *$ & $1.15 * * *$ & $1.53 * * *$ & $1.10 * * *$ & $1.56 * * *$ \\
\hline & $(0.25)$ & $(0.27)$ & $(0.22)$ & $(0.23)$ & $(0.25)$ \\
\hline \multirow[t]{2}{*}{$65-74$} & $2.04 * * *$ & $1.43 * * *$ & $1.38 * * *$ & $0.73 * * *$ & $1.41 * * *$ \\
\hline & $(0.26)$ & $(0.29)$ & $(0.27)$ & $(0.28)$ & $(0.28)$ \\
\hline \multicolumn{6}{|l|}{ Education ref. None } \\
\hline \multirow[t]{2}{*}{ GCSE O level or lower } & $0.48 * *$ & 0.27 & $0.57 * *$ & 0.42 & $0.54 * *$ \\
\hline & $(0.22)$ & $(0.22)$ & $(0.27)$ & $(0.27)$ & $(0.27)$ \\
\hline \multirow[t]{2}{*}{ At least one A level } & $0.84 * * *$ & $0.57 * *$ & 0.36 & 0.14 & 0.30 \\
\hline & $(0.24)$ & $(0.25)$ & $(0.25)$ & $(0.25)$ & $(0.26)$ \\
\hline \multirow[t]{2}{*}{ Degree or equivalent } & $0.95 * * *$ & $0.62 * *$ & $0.85^{* * *}$ & $0.51 *$ & $0.73 * *$ \\
\hline & $(0.24)$ & $(0.25)$ & $(0.27)$ & $(0.27)$ & $(0.29)$ \\
\hline \multicolumn{6}{|l|}{ Household income ref.£0-299 } \\
\hline \multirow[t]{2}{*}{$£ 300-499$} & $0.58 * *$ & $0.40 *$ & 0.33 & 0.27 & 0.35 \\
\hline & $(0.23)$ & $(0.24)$ & $(0.28)$ & $(0.28)$ & $(0.28)$ \\
\hline \multirow[t]{2}{*}{$£ 500-999$} & $0.65 * * *$ & 0.37 & 0.29 & 0.12 & 0.31 \\
\hline & $(0.23)$ & $(0.24)$ & $(0.26)$ & $(0.26)$ & $(0.26)$ \\
\hline \multirow[t]{2}{*}{$>£ 1000$} & $0.76 * *$ & 0.23 & $0.49 *$ & 0.19 & $0.49 *$ \\
\hline & $(0.30)$ & $(0.32)$ & $(0.29)$ & $(0.29)$ & $(0.29)$ \\
\hline \multicolumn{6}{|l|}{ Homeownership status } \\
\hline \multirow[t]{2}{*}{ Homeowners } & & 0.11 & & $0.34 *$ & \\
\hline & & $(0.20)$ & & $(0.20)$ & \\
\hline \multicolumn{6}{|c|}{ Gross financial wealth, ref. $<£ 1000$} \\
\hline \multirow[t]{2}{*}{$1,000-4,999$} & & 0.02 & & 0.19 & \\
\hline & & $(0.25)$ & & $(0.23)$ & \\
\hline \multirow[t]{2}{*}{$5,000-9,999$} & & 0.16 & & 0.27 & \\
\hline & & $(0.26)$ & & $(0.24)$ & \\
\hline \multirow[t]{2}{*}{$10,000-49,999$} & & $0.51 * *$ & & $0.65 * * *$ & \\
\hline & & $(0.24)$ & & $(0.20)$ & \\
\hline \multirow[t]{2}{*}{$50,000-99,999$} & & $0.76 * *$ & & $1.10 * * *$ & \\
\hline & & $(0.30)$ & & $(0.24)$ & \\
\hline More than 100,000 & & $1.38 * * *$ & & $1.26^{* * *}$ & \\
\hline & & $(0.32)$ & & $(0.26)$ & \\
\hline Father's s.e. class ref. Prof & & & & & \\
\hline Inter. -skilled non-manual & & & & & $-0.45^{*}$ \\
\hline & & & & & $(0.24)$ \\
\hline Skilled manual & & & & & $-0.52 * *$ \\
\hline & & & & & $(0.25)$ \\
\hline Partly skilled or unskilled & & & & & $-0.55 * *$ \\
\hline & & & & & $(0.23)$ \\
\hline Constant & $6.90 * * *$ & $7.21 * * *$ & $7.17 * * *$ & $7.01 * * *$ & $7.65 * * *$ \\
\hline & $(0.29)$ & $(0.31)$ & $(0.35)$ & $(0.37)$ & $(0.42)$ \\
\hline Number of Obs. & 597 & 597 & 924 & 924 & 924 \\
\hline Adjusted R-squared & 0.153 & 0.179 & 0.073 & 0.111 & 0.0754 \\
\hline
\end{tabular}

Note: The sample includes all respondents aged 25-74 years old. Standard errors are reported in parentheses.*** indicates coefficient statistically significant at the $1 \%$ level, ** at the $5 \%$ level and * at the $10 \%$ level. Source: Own analysis of data from the BHPS (waves7-16) and the AIS (2004). 
Table 9: Probit marginal effects and OLS estimates of the change in the association between socio-economic status and inheritance: Probit and OLS interaction models

\begin{tabular}{lcccccc}
\hline \hline & \multicolumn{2}{c}{ Probit model } & & \multicolumn{2}{c}{ OLS } \\
\cline { 2 - 3 } \cline { 6 - 7 } Education ref. None & & & & & \\
Main effects & & & & & \\
GCSE o level or lower & $\left(0.05^{* * *}\right.$ & $0.04 * * *$ & & 0.16 & 0.16 \\
& $0.09 * * *$ & $0.08^{* * *}$ & & $0.24 * *$ & $0.21 *$ \\
At least one A level & $(0.01)$ & $(0.01)$ & & $(0.12)$ & $(0.12)$ \\
& $0.16^{* * *}$ & $0.14 * * *$ & & $0.43 * * *$ & $0.40 * * *$ \\
Degree or equivalent & $(0.02)$ & $(0.02)$ & & $(0.12)$ & $(0.12)$
\end{tabular}

Interaction effects

GCSE o level or lower*1996-2005

$\begin{array}{cccc}0.05^{*} & 0.05^{* *} & 0.40 & 0.43 \\ (0.03) & (0.03) & (0.27) & (0.27) \\ 0.02 & 0.02 & 0.33 & 0.34 \\ (0.02) & (0.02) & (0.26) & (0.26) \\ 0.02 & 0.02 & 0.64 * * & 0.66 * * \\ (0.02) & (0.02) & (0.27) & (0.27)\end{array}$

\section{Homeownership status}

Main effects

Homeowners

Interaction effects

Homeowners*1996-2005

$\begin{array}{ll}-0.01 & -0.01 \\ (0.01) & (0.20)\end{array}$

Number of Obs.

15,390

15,352

1,567

Pseudo/adjusted R- squared

Log-likelihood

Note: The analysis in this table includes people aged 25-74 years old. Standard errors are reported in parentheses. $* * *$ indicates coefficient statistically significant at the $1 \%$ level, $* *$ at the $5 \%$ level and * at the $10 \%$ level.

Source: Own analysis of pooled data from the BHPS (waves7-16) and the GHS (1995/96). 